DOI: $10.4274 /$ tpa.46.84

\title{
Yenidoğan döneminde dilate kardiyomiyopatinin nadir bir nedeni: ALCAPA sendromu
} A rare cause of dilated cardiomyopathy in the newborn period: ALCAPA syndrome

\author{
Kadir Babaoğlu, Köksal Binnetoğlu, Gürkan Altun, Gürkan Çetin*, Levent Saltık* \\ Kocaeli Üniversitesi Tıp Fakültesi Çocuk Sağı̆ğı ve Hastalılkları Anabilim Dall, Çocuk Kardiyolojisi Bilim Dalı, Kocaeli, Türkiye \\ *istanbul Üniversitesi Kardiyoloji Enstitüsü, Kalp Damar Cerrahisi Anabilim Dall, Istanbul, Türkiye \\ **IStanbul Üniversitesi Cerrahpaşa Tıp Fakültesi Çocuk Sağı̆̆ı ve Hastalılkları Anabilim Dall, Çocuk Kardiyolojisi Bilim Dall, Istanbul, Türkiye
}

\section{Özet}

Sol koroner arterin pulmoner arterden çıkış anomalisi olarak tanımlanan ALCAPA sendromunda kardiyomegali, kalp yetersizliği gibi yakınma ve bulgular genellikle yaşamın ikinci-üçüncü ayları sonrasında ortaya çıkar. Yenidoğan döneminde ise hastalar genellikle yakınmasız olup, bu dönemde tanı alan hasta sayısı oldukça azdır. Burada yenidoğan döneminde kalp yetersizliği tablosunda kliniğimize başvuran, elektrokardiyografisinde DI ve aVL'de derin ve geniş Q dalgaları, ve ST yüksekliği gibi miyokard iskemi bulguları bulunan bir olgu sunuldu. Ekokardiyografik incelemede dilate kardiyomiyopati ile birlikte sol koroner arterin pulmoner arterden çıktığı izleniminin alınması nedeniyle yapılan kalp kateterizasyonu ve anjiyografi ile tanı kesinleşti.

Bu olgunun sunulması ile ALCAPA sendromunun yenidoğan döneminde bile dilate kardiyomiyopatiye yol açarak bulgu verebileceği vurgulanmak istenmiş ve bu hastalığa olan farkındalığı artırmak amacı güdülmüştür. (Türk Ped Arş 2011; 46: 256-8)

Anahtar sözcükler: Dilate kardiyomiyopati, sol koroner arterin pulmoner arterden çıkıs anomalisi, yenidoğan

\section{Summary}

Anomalous origin of the left coronary artery from the pulmonary artery (ALCAPA) is a rare congenital heart defect. ALCAPA is asymptomatic in many cases in newborn periode. It is mostly diagnosed in the first few months. In this case report, we present a newborn with ALCAPA who admitted to our clinic with heart failure occurred at an earlier age than expected. The electrocardiography showed deep wide Q waves in D1 and aVL, ST elevation in leads V1-V6. Echocardiography revealed a dilated cardiomyopathy and left main coronary artery originates from pulmonary artery. Diagnosis was confirmed by coronary angiography. In this report, we emphasized that ALCAPA may cause dilated cardiomyopathy also in newborn period and we aimed that enhanced awareness of this disease. (Turk Arch Ped 2011; 46: 256-8)

Key words: Anomaous origin of the left coronary artery from the pulmonary artery, dilated cardiomyopathy, newborn

\section{Giriş}

Sol koroner arterin pulmoner arterden çıkış anomalisi olarak tanımlanan ALCAPA (Anomalous Origin of the Left Coronary Artery from the Pulmonary Artery) sendromu tüm doğumsal kalp anomalilerinin \% 0,5'ini oluşturur. Canlı doğan çocuklarda görülme sıklığı 1/300 000'dir (1). Bu anomali ile doğan çocukların \% 87'si süt çocukluğu döneminde belirti verir ve \%65 ile \%85'i bir yaşından önce ve özellikle 2-3 ay civarında tedaviye dirençli kalp yetersizliği ile kaybedilirler (2).

Dilate kardiyomiyopati (DKM) ve konjestif kalp yetersizliği bulunan 28 günlük hastada klinik, elektrokardiyografi (EKG) ve ekokardiyografi (EKO) bulguları ile tanıya yönelik olarak yapıIan anjiyografi sonucunda ALCAPA sendromu tanısı konuldu. $\mathrm{Bu}$ olgunun sunulması ile ALCAPA sendromunun yenidoğan döneminde bile DKM'ye yol açabileceği vurgulanmak istenmiş ve bu hastalığa olan farkındalığı artırmak amacı güdülmüştür.

Yazışma Adresi/Address for Correspondence: Dr. Köksal Binnetoğlu, Kocaeli Üniversitesi Tıp Fakültesi Çocuk Sağlığı ve Hastalıkları Anabilim Dalı, Çocuk Kardiyolojisi Bilim Dalı, Kocaeli, Türkiye E-posta: koksaldr@yahoo.com Geliş Tarihi/Received: 17.11.2009 Kabul Tarihi/Accepted: 08.03.2011 


\section{Olgu}

Yirmi sekiz günlük kız çocuğu hızlı nefes alıp verme, emerken morarma nedeni ile acil polikliniğimize başvurdu. Bir hafta öncesine kadar başka bir yakınması olmadığı, hızı nefes alıp verme ve emerken morarma yakınmalarının son bir gündür arttığı öğrenildi. Fizik muayenede ağırlık 3750 gr (2550. persantil), boy $55 \mathrm{~cm}$ (50. persantil), baş çevresi $37 \mathrm{~cm}$

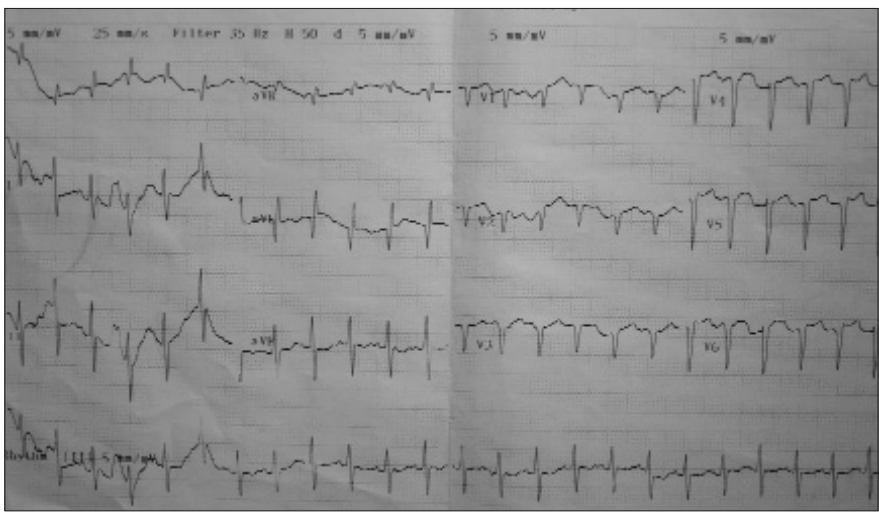

Şekil 1. Elektrokardiyografide D1 ve AVL de derin Q dalgaları ve göğüs derivasyonlarında ST dalga yüksekliği görülmektedir

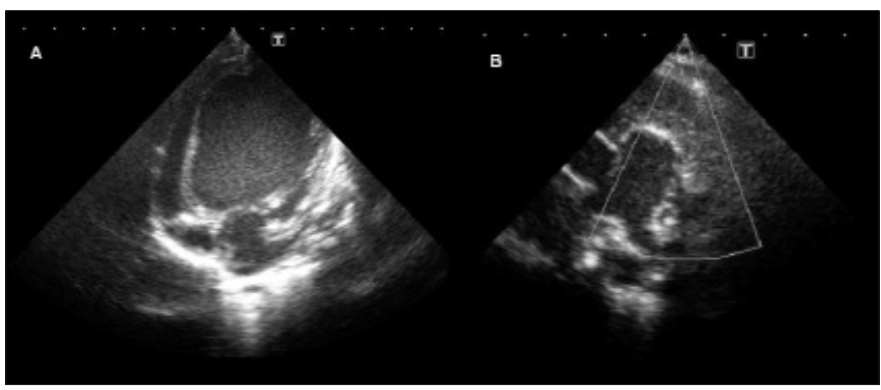

Şekil 2. A, Ekokardiyografide dört boşluk görüntüde olup, sol ventrikül belirgin geniş izlenmektedir. B, Ekokardiyografideki parasternal kısa eksen görüntüde sol koroner arterin pulmoner arterden çıktığı görülmektedir

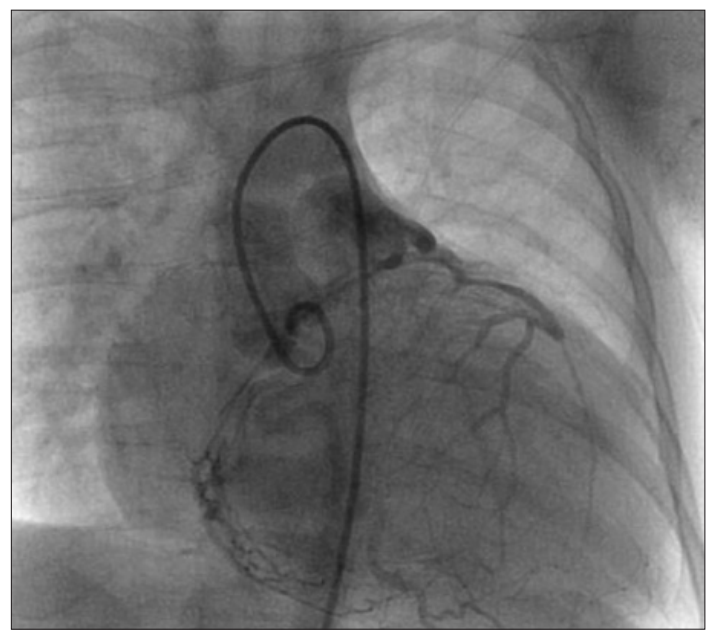

Şekil 3. Anjiyografide aort kökü enjeksiyonunda önce sağ koroner arterin daha sonra kollateraller aracılığıyle sol koroner arterin ve daha sonra pulmoner arterin kontrast madde ile dolduğu izlenmektedir.
(50-75. persantil), kalp tepe atımı 158/dak, kan basıncı 67/48 $\mathrm{mmHg}$, solunum sayısı 80/dak. idi. Karaciğer $4 \mathrm{~cm}$ ele geliyordu, mezokardiyak odakta $2 / 6$ şiddetinde sistolik üfürüm vardı. Telekardiyografide kardiyotorasik indeks \%62, EKG'de $D I$ ve aVL'de derin $Q$ dalgaları ve diğer göğüs derivasyonlarında ST yüksekliği saptandı (Şekil 1). Kan sayımında $\mathrm{Hb}$ 12,4 g/dl, Htc \% 37 , beyaz küre: 3840/mm3, trombosit: 471 000/mm3'dü. BUN: 5,5 mg/dl, kreatinin: 0,3 mg/dl, SGOT: 15 U/L, SGPT: $53 \mathrm{U} / \mathrm{L}, \mathrm{Na}^{+}: 138 \mathrm{mEq} / \mathrm{L}, \mathrm{K}^{+}: 4 \mathrm{mEq} / \mathrm{L}, \mathrm{Ca}^{+2}: 10$ $\mathrm{mg} / \mathrm{dl}$ idi. Kalp yetersizliği nedeni ile bakılan "brain natriurectic pepdide" (BNP) düzeyi 2422 pg/ml ( $\mathrm{N} \leq 100)$, EKG' de iskemi bulguları saptanması nedeniyle bakılan troponin-I: 2,38 ng/ml ( $\mathrm{N} \leq 0.03$ ) bulundu. Ekokardiyografide sol kalp boşlukları normalden geniş ve sol ventrikül sferikti. Kalp kasılmaları azalmıştı (kısalma fraksiyonu: \%16). Önemli derecede mitral yetersizlik ve orta derecede triküspit yetersizlik saptandı. Sağ ventrikül basıncı $60 \mathrm{mmHg}$ idi. Sağ koroner arterin normal yerinden çıktığı ve geniş olmadığı görüldü. Sol koroner arterin ise pulmoner arterden çıktığı izleniminin alınması (Şekil 2) nedeniyle hastada ALCAPA sendromu düşünülerek kalp kateterizasyonu ve anjiyografi yapılmasına karar verildi. Anjiyografide sol koroner arterin pulmoner arterden köken aldığı görülerek tanı kesinleştirildi. (Şekil 3) Hasta operasyona gönderildi. İntrapulmoner tünel ile anormal koroner arterin aortaya bağlantısı sağlandı. Ancak hasta operasyon sonrası erken dönemde kaybedildi.

\section{Tartışma}

ALCAPA sendromu nadir görülmekle birlikte tedavi edilmediğinde yaşamın ilk 1-2 yılında yüksek bir ölüm oranına sahiptir. Bu hastalığın patofizyolojik ve klinik özellikleri sol ventrikül miyokardının perfüzyonu ile doğrudan ilişkilidir. Bu anomali, aort ve pulmoner arterin gerek doygunlukları, gerekse basınçlarının benzer olması nedeniyle fetal dönemde iyi seyredebilir. Doğum sonrası pulmoner damar direnci düşmeye başlar ve pulmoner arterden sol koroner artere kan akışı gittikçe azalır ve sol ventrikül perfüzyonu sağ koroner arter ve sol koroner arter arasında gelişen kollaterallere bağlı kalır. Kollateral sayısı veya sol koroner arterden düşük basınçlı pulmoner artere olan kaçış sendromu, sol ventrikül miyokard perfüzyon yeterliliğini ya da iskemi derecesini belirler $(3,4)$. Bu patofizyoloji nedeniyle hastaların \%85'inde klinik bulgular genellikle doğumdan 2-3 ay sonra ortaya çıkar (5). Olguların büyük kısmı yaşamın ilk bir yılı içerisinde kalp yetersizliği tablosu ile kliniğe getirilen bebeklerdir. Geri kalan \%15 olguda ise kalp sorunlarının ortaya çıkması erişkin yaşlara kadar gecikebilir $(5,6)$. Yenidoğan döneminde ise çok daha nadir görülmektedir.

Walsh ve ark.'larının (7) çalışmasında 5 yıl içinde saptadıkları 11 olgunun tanı yaşı ortalama 4,5 ay olarak bulunmuştur ve bu çalışmada bir olgunun tanı yaşının iki hafta olduğu belirtilmiştir . Floren ve ark.'larının (8) çalışmasında ise 27 olgu değerlendirilmiş ve tanı yaşı üç ay-54 ay arasında saptanmıştır. Bu çalışmada yenidoğan döneminde tanı alan olgu bildirilmemiştir. Diğer bir çalışmada ise 13 yılda tanı konan toplam yedi olgudan sadece bir tanesi yenidoğan döneminde tanı almıştır (9).

Dilate kardiyomiyopati tanısı alan çocuklarda tedavi edilebilir bir durum olan ALCAPA'nın saptanması çok önemlidir. 
Olgular sıklıkla DKM ön tanısı alıp özellikle metabolik hastalıklar açısından uzun süren tetkik edilmekte, çoğu zaman da idiyopatik DKM olarak kabul edilmekte, ve asıl nedene yönelik tedavi yapılmadığı için kaybedilmektedirler. Dilate kardiyomyopati ile başvuran olgularda ALCAPA tanısını gözden kaçırmamak için EKG ve EKO'da bazı ipuçları tanımlanmıştır. Elektrokardiyografik bulgular doğrudan sol ventrikül miyokardının perfüzyon derecesi ile ilişkilidir. Elektrokardiyogramda DI, aVL ve V4-V6'da derin ve dar $Q$ dalgaları, sol ventrikül hipertrofisi ve sol eksen sapması temel özellikleri oluşturur (5). Bununla birlikte bu bulgular özgül olmayıp diğer kardiyomiyopatilerde de görülebilir. Ekokardiyografideki incelemede sağ koroner arterin geniş olması, sol koroner arterin aorttan çıkışının görülmemesi, papiller kasların ekojenitesinde artma görülmesi ve sol koroner arterin pulmoner arterden çıktığının izlenmesi temel özellikleri oluşturur. Yapılan çalışmalarda EKO'da belirgin özellikler için yanlış negatif sonuçlar bildirilmiştir. Bir çalışmada ALCAPA tanısı alan hastaların \%50'sinde ilk EKO incelemesinde yanlış negatif olarak sol koroner arterin aorttan çıktığı izlenimi alındığı belirtilmiştir (10). Chang ve Alada'nın (11) çalışmasında bu oran \%71 olarak bulunmuştur. Sözkonusu çalışmada EKO'daki yanlış negatif sonuçların en az hastaların yarısından fazlasında olabilmesi ve bu hastalığın özellikle idiyopatik DKM ile karışabilmesi nedeni ile bir ölçme sistemi geliştirmiş̧lerdir. Elektrokardiyogramda aVL'de QT paterni, 3 mm'den derin $Q$ dalgası olması ve $T$ dalga negatifliği; ekokardiyografide sağ koroner arter çapının aort "anülüsüne" oranının artması $(\geq 0,14)$, papiller kas ekojenitesinin artması ve pulmoner artere doğru artmış akım saptanması gibi özellikler birlikte değerlendirildiğinde ALCAPA tanısında \%100 duyarlılık ve \%91 özgüllüğe ulaşılacağı bildirilmiştir.

Bu hastalık ile ilgili yapılan çalışmalar sonucunda hekimlerin bilgi düzeyi ve deneyimi arttıkça hastalığın sıklığı değişkenlik göstermiştir. Önceleri 1/300 000 sıklığı olduğu belirtilirken 2008 yılında Brotherton ve ark.'Iarının (12) canlı yenidoğanlar arasında yaptığı çalışmada bu rakam 1/4 243 olarak bulunmuştur.

ALCAPA sendromunun kesin tedavisi cerrahidir. Medikal tedavi daha çok miyokard kasıımasını artırmaya yönelik olarak yapılır. Erken tanı ve tedavi daha hızlı bir miyokardiyal düzelme sağlar. Michielon ve ark. (13) sol ventrikül işlevlerinin düzelme potansiyelinin küçük süt çocuklarında daha iyi olduğunu vurgularken, Ando ve ark. (14) cerrahi tedavi sonrası erişkinlerde de çocuklarda olduğu kadar ventrikül işlevinin düzeldiğini belirtmişlerdir. Hastamız ise geç yenidoğan dönemi gibi erken bir dönemde opere edilmesine rağmen yaygın miyokard iskemisi nedeniyle sol ventrikül işlevleri düzelmemiş ve operasyon sonrası erken dönemde durumu hızla bozularak kaybedilmiştir.
Sonuç olarak tedavi edilmediği zaman ölümcül seyreden bu hastalığın cerrahi tedavi ile kesin çözümü olduğu bilinmelidir. Illk bulguların ortaya çıkması genellikle 2-3 aylık dönemden sonra olmasına rağmen yenidoğan döneminde de DKM ile başvuran hastalarda klinik, telekardiyografi, EKG bulguları önemle incelenmeli, EKO'da ALCAPA'ya ait ipuçları dikkatle araştııımalı ve erken tedavi imkanı sağlanmalıdır.

\section{Kaynaklar}

1. Keith JD. The anomalous of the left coronary artery from the pulmonary artery. Br Heart J 1959; 21: 149-61.

2. Metherne GP, Lim DS. Congenital anomalies of the coronary vessels and the aortic root. In: Allen HD, Driscoll DJ, Shaddy RE, Feltes TF (eds). Moss and Adams Heart Disease in infants, children and adolescents. 7th ed. Philadelphia: Lipincott Williams \&Wilkins, 2008: 709.

3. Inekwaba FN, Davidson KG, Ogilvie B, et al. Anomalous origin of the left coronary artery from the pulmonary artery with coronary artery steal in adults. Report of two cases and review of the literature. Thorax 1976; 31: 337-45

4. Akalın F, Topçu B. Her iki koroner arterin pulmoner arterden köken alması: bir vaka takdimi. Çocuk Sağlığı ve Hastalıkları Dergisi 2009; 177: 127-30.

5. Perloff JK. Clinical recognition of congenital heart disease. 5th ed. Philadelphia: Saunders, 2003: 430-42.

6. Liberthson RR. Sudden death from cardiac causes in children and young adults. N Engl J Med 1996; 334: 1039-44.

7. Walsh MA, Duff D, Oslizlok P, et al. A review of 15-year experience with anomalous origin of the left coronary artery. Ir J Med Sci 2008; 177: 127-30.

8. Florent C, Vouhe PR, Khoury W, et al. Anomalous left coronary artery arising from the pulmonary artery: a series of 27 infants undergoing operation in the first years of life. J Cardiothorac Anesth 1988; 4: 445-9.

9. Dahle G, Fiane AE, Lindenberg HL. ALCAPA, a possible reason for mitral insuficiency and heart failure in young patients. Scand Cardiovasc J 2007; 41: 51-8.

10. Karr SS, Parness IA, Spevak PJ, et al. Diagnosis of anomalous left coronary artery by Doppler color flow mapping: distinction from other causes of dilated cardiomyopathy. J Am Coll Cardiol 1992; 19: 1271-5.

11. Chang RR, Allada V. Electrocardiographic and echocardiographic features that distinguish anomalous origin of the left coronary artery from pulmonary artery from idiopathic dilated cardiomyopathy. Pediatr Cardiol 2001; 22: 3-10.

12. Brotherton H, Philip RK. Anomalous left coronary artery from pulmonary artery (ALCAPA) in infants: a 5-year review in a defined birth cohort. Eur J Pediatr 2008; 167: 43-6.

13. Michielon G, Di Carlo D, Brancaccio G, et al. Anomalous origin of the left coronary artery from pulmonary artery: correlation between surgical timing and left ventricular function recovery. Ann Thorac Surg 2003; 76: $581-8$.

14. Ando M, Mee RB, Duncan BW, et al. Creation of a dual-coronary system for anomalous origin of the left coronary artery from pulmonary artery utilizing the trapdoor flap method. Eur J Cardiothorac Surg 2002; 22: 576-81. 